\title{
Self Perception of Health and Health Promoting Activities Among the Elderly
}

\author{
${ }^{1}$ Lanre-Babalola Folake 0 \\ Department of Behavioral Studies \\ Redeemer's University, Ede,Osun State. Nigeria.
}

\begin{abstract}
Self-perceived health status is the interpretation that individuals make of their health status and daily life experiences, and this could be linked to as the social, cultural, and historical context in which individuals live. Therefore, identifying the determining factors involved in self perceived health status is essential to understand behaviour and how to assess individual needs. However; most of these studies were confined to Western populations; moreover the possible effect of age on health cannot be over-emphasized; hence the need for a study of this nature.
\end{abstract}

Questionnaire was utilized to elicit information among 200 respondents on the areas of interest and the study was conducted in Somolu Local Government Area, Lagos State. Data was analyzed using statistical package for social sciences (SPSS) and the hypotheses were tested using the chi-square $\left(\mathrm{X}^{2}\right)$ and pearson correlation statistical analysis test

Only $26 \%$ of the respondents perceive there health as excellent; indicating a need to pay attention to he health of the elderly in the country. Findings reveal relationships between some demographic variables like income, gender, literacy level and self perception of health among the elderly. There is also a relationship between health promoting activities and hospitalization among the elderly.

Health care providers need to be more compassionate and caring to the needs of the elderly; it is also recommended that elderly persons should be provided with free health services that

would make health delivery and health care services at little or no cost.

Keywords: Self perception, Health, Elderly, Activities.

\section{BACKGROUND}

Old age is inevitable as people grow old from time to time, however; old age has its own challenges particularly in the area of health. Old age often brings about health problems and decreasing functional capacity which may affect the sense of wellbeing of an individual. In this regard, the goal of health for the elderly in the society may not be that of freedom from diseases but the possibility of having a good life despite illness and decreasing capacities (Lawton, 2002). Feelings about life are subjective and what is considered as important for wellbeing by one person may not be so regarded by another. Also, a chronic health condition occurring in the setting of a developed country may have a lower impact on the Quality of Life $(\mathrm{QoL})$ on the patient than the same disease would have in a low income country where resources to ameliorate disability may be scarce. The subjective nature of Quality of life and the contextual nature of its assessment inform the World Health Organization's definition of it as: "an individual's perception of his/her position in life in the context of the culture and value systems in which he/she lives, and in relation to his/her goals, expectations, standards and concerns" (The WHOQOL Group, 2005). Thus Quality of Life (QoL) reflects a broad view of subjective wellbeing and life satisfaction that encompasses mental and physical health, material wellbeing, interpersonal relationship within and without the family, work and activities within the communities, personal development and fulfillment and active recreation (Wikby 2006, Wankata et al., 2008). Self-perceived health status is the interpretation that individuals make of their health status and daily life experiences. This process requires knowledge about health and disease, mediated by prior experience as well as the social, cultural, and historical context in which individuals live (Gilbert, 1994). With respect to the health management process, self-perceived health status in a population helps guide political and social conditions aimed at improving both health and quality of life.

Therefore, identifying the determining factors involved in self perceived health status is essential to understand behavior and how to assess individual needs. In evaluating health status, knowing the perspective of individuals about their own health is an important prerequisite for increasing adherence to healthy behavior (Benyaminy et al., 2004). In the case of the elderly, this aspect becomes even more relevant, since, even in countries with

\footnotetext{
${ }^{1}$ Corresponding Author: lanrebabalolaf@run.edu.ng
} 
programs directed specifically to this age group, the main reason these individuals do not seek dental treatment is their not recognizing the need for oral health care.

Recent study on Africa elderly suggests a growing prevalence of morbidity and poor health status along with significant increases in longevity among them. Thus, while in the country where maternal and child health care indicators are still far from goals, ageing has emerged as another long term burden over the country's health care system. Decreases in infant mortality and fertility combined with an increasing life expectancy have led a large number of countries to have a growing proportion of aged individuals with specific healthcare needs. As the prevalence of most chronic diseases is high in old age, societies need changes in their healthcare systems capable of coping with the growing concerns of elderly health. Like many developing countries, the health system of Nigeria is inadequate to promote, support, and protect health and social well-being of the elderly due to lack of human and financial resources.(Soyombo 1996,2003) The prevailing situation stands as major concern among policy makers to extend socio-economic security and proper health care for their ageing population specifically to the poor section of the society. Therefore, the necessity of analyzing the current Health pattern and demand for healthcare among elderly is of importance.

\section{Statement of Problem}

Health is central for living, work and income. It is also a precondition for development. Thus, everybody, including older persons should be enabled to continue with income-generating work for as long as they are agile and are able to do so productively. However, frequently it is assumed that old people are challenged by deteriorating health and does not need to generate income given their lifelong accumulation of income. Several studies are available to support the fact that though health declines with age, regardless of this; health ratings and perceptions vary across individuals, many older people still rate their health based on situations, experiences and lifestyle. A number of studies have also found that self-ratings of health among elderly adults are valid measures of the respondent's objective health status and match up as well to physician evaluations. However; most of these studies were confined to Western populations; (Irwin 2003, Guigoz 2006; Sidenvall et al 2006). In addition to these; the possible effect of age on health cannot be over-emphasized; hence the need for a study of this nature.

\subsection{Research Questions}

The following research questions are generated as follows:

$>$ How do the elderly in Nigeria perceive their health status?

$>$ What are the factors related to self perception of health?

$>$ What health improvement activities do the elderly engage in?

$>$ What are the common causes of hospitalization among the elderly?

\subsection{Objectives of the Study}

The general objective of this study is to examine self-perception of health and health promoting activities among the elderly.

\subsection{The specific objectives are as follows}

$>$ To explore the perception of health status among the elderly.

$>$ To identify factors influencing perception of health among the elderly.

$>$ To document frequency and common causes of drug use and hospitalization among the elderly.

$>$ To document practice and perception of Health Promoting Activities among the elderly.

\subsection{Significance of the Study}

The findings will demonstrate the important roles of psychological resources and subjective perceptions and suggest a need to consider them when planning interventions in promoting older people's health, preventing disease and managing chronic illnesses. Training all health providers in working with issues and disorders related to ageing is therefore important. It is an important question in predicting morbidity and mortality. Older individuals with lower levels of education and economic status and various types of health problems (more chronic conditions, greater disability, poorer vision, and greater numbers of sick days) will benefit to understand negative self-perception of aging and health and also it will help to focus on the long-term care of older adults suffering from mental disorders, as well as to provide caregivers with education, training and support. Individuals' self-assessment of their health may include aspects that are difficult to capture clinically, such as incipient disease, disease severity, physiological and psychological reserves, and social function. 


\subsection{Limitation of the Study}

A major limitation that should be acknowledged in this study is the fact that all information on self perception of health are self reported; such information may well be related to respondents state of health as at time of interview. Also, the information in this reseach is limited to the elderly men and women in Lagos Mainland Local government.

\section{BRIEF REVIEW OF LITERATURE}

Health - related quality of life is defined as a part of quality of life, including the subjective perception of symptoms of illness and objective measurements of diseases as well as the individual dimension of well being (Rothenberg 2000). Self perceived health is every individual's own perception of their health including important dimensions of life that are meaningful to their health.

Self perceived health, self assessed health and self rated health are synonymous and have been used in different studies to estimate the same thing; the individuals own perception of their health. The question of self - perceived health is common in medical and social investigations (Marengoni 2009; Rosén \& Haglund, 2005) and has been found to be an important question in predicting morbidity and mortality (Maaten et al., 2008; Lyyra et al., 2009). Health is also explained by the absence of disease and by survivorship in longitudinal studies, and by different subjective assessments of grades of bodily (Vandevjvere et al., 2008), mental and cognitive function and the ability to perform different activities (Patel et al., 2006). Individuals perceive their health as good even if they have diseases and symptoms of illness (Rosén \& Haglund, 2005).

\section{Achieving Health Promotion Behavior Change among Older People}

Historically, healthy ageing has been conceptualized from a purely medical perspective with the focus being on the absence of disease and disease related disability. The World Health Organization (WHO) declaration that health is defined as "a state of complete physical, mental, and social well-being, and not merely the absence of disease and infirmity". Successful ageing is defined as the avoidance of disease and disease-related disability, the maintenance of high cognitive and physical functional capacity, and an active engagement with life; that is, maintaining physical, mental and social health.

Health promotion priorities change for individuals and cohorts as they grow older (Hickey \& Stilwell, 2009). Generally as people get older they are confronted with multiple losses of health, independence, roles, possessions, friends and family (Alpellros, 2005). Hickey and Stilwell (2001) suggest that the goal of health promotion in the elderly should be to prevent the progression of disease and the management of disabilities with the ultimate aim being to allow older people to maintain their functional independence for as long as possible (Adamson et al, 2009). The health and conditions of older people is very complex, often impacting on an individual's thoughts and feelings as well as physiological mechanisms, and therefore demands a holistic approach (Anthony, 2008).

\section{THEORETICAL APPROACH}

Health promotion from the behavioral approach focuses on implementing interventions to change or remove behavioral health risk factors. Interventions from this perspective target a particular behavioral risk factor associated with a particular negative health outcome(s); they target a population performing the behavioral risk factor and Endeavour to promote health through various strategies. These strategies may include raising awareness of health risks through health education, social marketing, and policies that support lifestyle choices. There are a number of theoretical approaches that have been shown to predict and describe health behavior change. Four key models have been identified; these are the health belief model (HBM), theory of planned behavior (TOPB), Trans theoretical model (TTM) and the communication enhancement model (CEM). The health belief model is useful to understand the formation of the intention to perform a health behavior; the constructs in the theory of planned behavior have been found to predict performance of a particular behavior; and the stages of change model allows us to understand an individual's readiness to change and the Processes and patterns of change (Bowling, 2008). The aforementioned models illustrate the importance of appropriate communication in empowering older people to take ownership over their health. An understanding of each of these models, particularly the processes and patterns of change are important as they allow for the implementation of effective interventions that are relevant to each individual's readiness to change.

\section{Methodology}


The research design used in this study is the quantitative research design, the survey method was utilized to elicit information on the areas of interest. The study was conducted in Somolu Local Government Area, Lagos State. The data gathered in the study was edited and screened for possible errors. The univariate, bi-variate and hypotheses variable were tabulated and analyzed using statistical package for social sciences (SPSS) and the findings were presented in percentages $(\%)$. Also the hypotheses were tested using the chi-square $\left(\mathrm{X}^{2}\right)$ and Pearson correlation statistical analysis test.

\section{ViI. Presentation of Results}

Table1. Socio-Demographic Profile Of Respondents

\begin{tabular}{|c|c|c|}
\hline Sex & Frequency & Percent \\
\hline Male & 96 & 48 \\
\hline Female & 104 & 52 \\
\hline \multicolumn{3}{|l|}{ Age category } \\
\hline $51-60$ years & 92 & 46 \\
\hline $61-70$ years & 48 & 24 \\
\hline 71 and above & 60 & 30 \\
\hline \multicolumn{3}{|l|}{ Marital status } \\
\hline Single & 12 & 6 \\
\hline Married & 156 & 78 \\
\hline Divorced & 28 & 14 \\
\hline Widow & 4 & 2 \\
\hline \multicolumn{3}{|c|}{ Educational qualification } \\
\hline SSCE/WASC & 44 & 22 \\
\hline OND/NCE & 60 & 30 \\
\hline HND/BSC/BA & 96 & 48 \\
\hline \multicolumn{3}{|l|}{ Employment status } \\
\hline Employed & 88 & 44 \\
\hline Non-employed & 112 & 56 \\
\hline \multicolumn{3}{|l|}{ Monetary support } \\
\hline Work & 36 & 18 \\
\hline Pension & 84 & 42 \\
\hline Children & 56 & 28 \\
\hline Relative & 24 & 12 \\
\hline \multicolumn{3}{|l|}{ Religion } \\
\hline Christianity & 136 & 68 \\
\hline Islam & 64 & 32 \\
\hline \multicolumn{3}{|l|}{ Level of income } \\
\hline $\mathrm{N} 50,000-\mathrm{N} 100,000$ & 84 & 42 \\
\hline $\mathrm{N} 150,000-\mathrm{N} 200,000$ & 60 & 30 \\
\hline $\mathrm{N} 250,000$ and above & 56 & 28 \\
\hline
\end{tabular}

Source: Field survey 2014.

Forty eight $48 \%$ of the respondents are male while $52 \%$ are female respondents, $46 \%$ of the respondents fall within age category of $51-60$ years, $24 \%$ of respondents falls within the age group of $61-70$ years while $30 \%$ of the respondents age category of 71 years and above, also that $6 \%$ of the respondents are single, $78 \%$ of the respondents are married, $14 \%$ of the respondents are divorced while $2 \%$ of the respondents are widowed. This data shows that majority of respondents are married. Furthermore $22 \%$ of the respondents are secondary school certificate holders, $30 \%$ of the respondents are either OND/NCE holders while $48 \%$ of the respondents are either $\mathrm{HND} / \mathrm{BSC} / \mathrm{BA}$ holders, $44 \%$ of the respondents are employed while $56 \%$ of the respondents are non-employed. Meanwhile; $18 \%$ of the respondents rely on their work as the source of their monetary support, $42 \%$ of the respondents rely on pension as their monetary support, $28 \%$ of the respondents depend on their children for monetary support while $24 \%$ of the respondents rely on family relative for monetary support. The data shows that $42 \%$ of the respondents' income level is between N50,000 - N100,000, 30\% of the respondents' income level is between N150,000 - N200,000 while 20\% of the respondents' income level is between N250,000 and above. 


\subsection{Hypothesis One}

\section{AnAlysis BaSEd on Central VARIABLES OF STUDY}

$\mathbf{H}_{\mathbf{0}}$ : There is no relationship between income level and self perception of health among the elderly

$\mathbf{H}_{1}$ : There is a relationship between income level and self perception of health among the elderly

Table2. Relationship Between Level of Income and Self Perception of health among the elderly

\begin{tabular}{|l|l|l|}
\hline & & Perception of health among elderly \\
\hline Level of income & Pearson Correlation & 0.170 \\
\hline & Sig. (2 tailed) & 0.016 \\
\hline & N & 200 \\
\hline
\end{tabular}

**. Correlation is significant at the 0.05 level (2-tailed)

Using the Pearson Correlation of 0.170 , there is a positive correlation between level of income and self perception of health among the elderly. This implies that the level of income of an elderly person tend to have an effect on the state of their state of health. Also, the 'p' value which is 0.016 is less than the 0.05 level of significance, thus, the Null hypothesis is rejected and the Alternate hypothesis which states that there is a relationship between income level and self perception of health among the elderly is accepted indicating that lack of sufficient income on the part of the elderly tends to result to their bad state of health and vice versa.

\subsection{Hypothesis Two}

$\mathbf{H}_{\mathbf{0}}$ : There is no significant relationship between level of literacy of elder and self perception of health among the elderly.

$\mathbf{H}_{1}$ : There is a significant relationship between level of literacy of elder and self perception of health among the elderly.

Table3. Relationship between level of literacy and self perception of health among the elderly

\begin{tabular}{|l|l|l|}
\hline & & Perceived effect of age on health \\
\hline Educational qualification & Pearson Correlation & 0.277 \\
\hline & Sig. (2 tailed) & 0.000 \\
\hline & N & 200 \\
\hline
\end{tabular}

**. Correlation is significant at the 0.01 level (2-tailed)

Using the Pearson Correlation of 0.277 , there is a positive correlation between level of literacy and self perception of health among the elderly. This implies that the level of literacy of the elderly tend to have an effect on the state of their health. Also, the 'p' value which is 0.000 is less than 0.01 level of significance, thus, the Null hypothesis is rejected and the Alternate hypothesis which states that there is a relationship between literacy level and self perception of health among the elderly is accepted. This implies that there is a correlation between literacy level and self perception of health among the elderly; this result shows that level at which an elderly person is educated tends to determine the importance such an elderly person attach to his or her health management.

\subsection{Hypothesis Three}

$\mathbf{H}_{\mathbf{0}}$ : There is no significant relationship between gender and Perception of Health among

the elderly.

$\mathbf{H}_{1}$ : There is a significant relationship between gender and Perception of Health among the elderly.

Table4. Relationship between Gender and self perception of health among the elderly

\begin{tabular}{|l|c|c|c|c|}
\hline Gender & \multicolumn{3}{|c|}{ Self perception of health } & Total \\
\hline & Excellence & Good & Bad & $96(100 \%)$ \\
\hline Male & $12(13 \%)$ & $20(21 \%)$ & $64(67 \%)$ & $104(100 \%)$ \\
\hline Female & $40(39 \%)$ & $44(42 \%)$ & $20(19 \%)$ & $200(100 \%)$ \\
\hline Total & $52(26 \%)$ & $64(32 \%)$ & $84(42 \%)$ & \\
\hline$X^{2}=46.880 ; d f=2 ;$ p-value $=0.000$ &
\end{tabular}

The chi-square value is 46.880 and the $\mathrm{p}$-value is 0.000 which is less than the significance level 0.05 , indicating that there is a significant relationship gender and self perception of health among the elderly. This analysis depicts a true reflection of reality in that women tend to have longer life span than men in society at old age. This statement also support general belief upheld by people in society as regards life-span of men and women. 


\subsection{Hypothesis Four}

$\mathbf{H}_{\mathbf{0}}$ : There is no significant relationship between health promoting activities and hospitalization among the elderly.

$\mathbf{H}_{1}$ : There is a significant relationship between health promoting activities and hospitalization among the elderly.

Table5. Relationship Between Health Promoting Activities and Hospitalization among the Elderly

\begin{tabular}{|l|l|l|l|}
\hline Health promoting activities & Hospitalization among the elderly & \\
\hline & Yes & No & Total \\
\hline Exercise & $41(56 \%)$ & $32(44 \%)$ & $73(100 \%)$ \\
\hline Weigh control & $30(52 \%)$ & $28(48 \%)$ & $58(100 \%)$ \\
\hline Check blood pressure & $52(93 \%)$ & $4(7 \%)$ & $56(100 \%)$ \\
\hline Medical check-up & $9(69 \%)$ & $4(31 \%)$ & $13(100 \%)$ \\
\hline Total & $132(66 \%)$ & $68(34 \%)$ & $200(100 \%)$ \\
\hline $\mathrm{X}^{2}=26.476 ; \mathrm{df}=3 ; \mathrm{p}$-value $=0.000$ & & \\
\hline
\end{tabular}

The chi-square value is 26.476 and the p-value is 0.000 which is less than the significance level 0.05 . Hence, the Null Hypothesis was rejected while the Alternative Hypothesis was accepted, indicating a significant relationship between health promoting activities and hospitalization among the elderly.

\section{Presentation of Results according to Research Objectives}

\section{OBJECTIVE 1: To Explore The Perception of Health Status among the Elderly}

The above objective revealed that $26 \%$ of the respondents perceive that heath condition is excellent, $32 \%$ of the respondents perceive that heath condition is good while $42 \%$ of the respondents perceive that heath condition is bad. Also, $58 \%$ of the respondents perceive that the effect of age on their health is high, $35 \%$ of the respondents perceive that the effect of age on their health is low while $8 \%$ of the respondents perceive that age have no effect on their health.

\section{OBJECTIVE 2: To Identify Factors Influencing Perception of Health among the Elderly.}

The above objective revealed that $24 \%$ of the respondents' purpose of visit to the hospital is due to one health problem or the other, $22 \%$ of the respondents' purpose of visit to the hospital is due to need for medical test/examination, $20 \%$ of the respondents' purpose of visit to the hospital is as a result of medical follow-up visit while this response is not applicable to $34 \%$ of the respondents.

\section{OBJECTIVE 3: To Document Frequency and Common Causes of Drug Use and Hospitalization among the Elderly.}

The above objective revealed that $24 \%$ of the respondents have experienced high blood pressure in the past 12 months, $22 \%$ of the respondents have experienced diabetes in the past 12 months, $18 \%$ of the respondents have experienced Asthma in the past 12 months, $28 \%$ of the respondents have experienced malaria in the past 12 months while $8 \%$ of the respondents have experienced joint pain in the past 12 months. This is an indication all respondents have one health challenge or the other which tends to them using drugs for their ailment

\section{OBJECTIVE 4: To Document Practice and Perception of Health Promoting Activities among the Elderly.}

The above objective revealed that $36 \%$ of the respondents engage in exercise as a form of their health promoting activities, $39 \%$ of the respondents engage in weigh control as a form of their health promoting activities, $38 \%$ of the respondents engage in checking of blood pressure as a form of their health promoting activities while $6 \%$ of the respondents engage in medical check-up as a form of their health promoting activities. Also, in another stance, $52 \%$ of the respondents strongly agreed health promoting activities would be of great benefit to the elderly, 34 of the respondents strongly agreed health promoting activities would be of great benefit to the elderly while $14 \%$ of the respondents remained indifferent on health promoting activities being of great benefit to the elderly.

\section{SUMMARY OF FINDINGS}

In summary there is a relationship between some demographic variables like income, gender, literacy level and self perception of health among the elderly. There is also a relationship between health promoting activities and hospitalization among the elderly. The study shows that various health challenges the elderly are being faced with one health challenge or the other and have resulted in one hospitalization at one time or the other and have probably prompted them to involve themselves in one health promoting activities or the other so as to improve 
their health condition and well-being. This study indicates that it is highly imperative for elderly to engage in at least one health promoting activity so as to enjoy good health.

\section{DISCUSSION}

This study majorly focuses on self perception of health and health promoting activities among the elderly in Lagos state. It is a common occurrence that the health of most aged people in society tends to deteriorate at old age as most old people often fall victims poor health condition. A number of them are not even aware of some health promoting activities that could help promote their state of health at old age. Therefore, this study highlights some health promoting factors which could possibly affect the self perception of the elderly towards their health.

Literatures were reviewed by other scholars within the area of study, literatures examined include Roubenoff's (2000) work on self-perceived health, Rothenberg's (2004) work on nutrition and ageing, Beck \& Ovesen's (1998) work on risk for malnutrition, Samson et al's (2000) work on achieving health promotion and behavioural change among older people, Sidenvall et al (2006) work on self-rated health and social comparisons and Larrson \& Thorsland (2006) work on perceived social support and health behaviours amongst other related literatures by several scholars of ageing and gerontology.

\section{CONCLUSION AND RECOMMENDATIONS}

There is a need to develop rational policy so as to provide efficient, effective, acceptable, cost-effective, affordable and accessible health services for the elderly, we need to understand the drivers of health seeking behaviour of the old people in an increasingly pluralistic health care system. This relates both to public as well as private sectors. Raising the socio-economic status through multi-sectoral development activities such as micro-credit, life-skill training and non-formal education have been shown to have a positive impact on health promoting activities of the elderly and their health seeking behaviour. Gender sensitive strategies and programmes need to be developed alongside. Health providers also need to be sensitized more towards the needs of the clients especially the old people in order to improve interpersonal communication. Although there is a fairly large infrastructure of formal and orthodox institutions for health provision, the quality needs to be improved. Moreover, it is strongly desirable to further nurture critical, creative and reflective thinking to reorient our health system. Health care providers need to be more compassionate and caring to the needs of the people they serve. They should possess integrity, creativity and sensitivity and be the role model within health care system and in communities most especially towards the dependent population (the elderly) in our society. The government should provide elderly persons with special social security that would make them less dependent on their children and family members, thus making them less vulnerable to poor health condition. Elderly persons should be provided with free health services that would make health delivery and health care services at little or no cost.

\section{REFERENCES}

[1] Adamson A., Collerton J., Davies K., Foster E., Jagger C., Stamp E., Mathers J. \& Kirkwood T. (2009): Nutrition i advanced age:dietary assessment in the Newcastle 85+ study. European Journal of Clinical Nutrition 63, 6 - 18.

[2] Anthony P. (2008): Nutrition Screening Tools for Hospitalized Patients. Nutrition in Clinical Practice 23, 373 - 382 .

[3] Appelros P. (2005): Characteristics of Mini - Mental State Examination 1 year after stroke. Acta Neurlogica Scandinavica 112, 88 - 92. Arber S. \& Cooper H. (1999): Gender differences in health in later life:the new paradox? Social Science \& Medicine 48, 61 - 76.

[4] Beck A.M. \& Ovesen L. (1998): At which body mass index and degree of weight loss should hospitalized elderly patients be considered at

[5] Benyamini Y., Leventhal E.A. \& Leventhal H. (2000): Gender Differences in Processing Information for Making Self - Assessment of Health. Psychosomatic Medicine 62, 354 - 364.

[6] Bowling A. (2008): Enhancing later life: How older people perceive active ageing? Aging \& Mental Health 12, 293 - 301. Chen C. - H., Bai Y. - Y., Huang G. - H. \& Tang S.T. (2007): Revisting the concept of malnutrition in older people. Journal of Clinical Nursing, doi:10.1111/j.1365 - 2702.2006.01867.67.

[7] Guigoz Y. ( 2006): The Mini Nutritional Assessment (MNA) review of the literature - What does it tell us? The Journal of Nutrition, Health \&Aging 10, 466 - 487.

[8] Irwin S. (2003): Interdependencies, values and the reshaping of difference:gender and generation at the birth of twentieth - century. British Journal of Sociology 54, 565 - 584. 
[9] Larsson K. \& Thorslund M. (2006): Chapter 8: old people $\square$ s health. Scand J Public Health Suppl 67, 185 - 98.

[10]Lawton M.P., Moss M., Fulcomer M. \& Kleban M.H. (2002): A Research and Service Oriented Multilevel Assessment Instrument. Journal of Gerontology 37, 91 - 99.

[11]Lyyra T. - M., Leskinen E., Jylhä M. \& Heikkinen E. (2009): Self - rated health and mortality in older men and women: A time - dependent covariate analysis. Archives of Gerontology and Geriatrics $\mathbf{4 8 ,}$ $14-18$

[12] Maaten S., Kephart G., Kirkland S. \& Andreou P. (2008): Chronic disease risk factors associated with health service use in the elderly. BMC Health Services Research 8.

[13] Marengoni A., Rizzuto D., Wang H.-X., Winblad B. \& Fratiglioni L. (2009): Patterns of Chronic Multimorbidity in the Elderly Population. J Am Geriatric Soc 57, 225-230.

[14] nutritional risk? Clinical Nutrition 17, 195 - 198.

[15]Rosén M. \& Haglund B. (2005): From healthy survivors to sick survivors - implications for the twenty - first century. Scandinavian Journal of Public Health 33, 151 - 155.

[16] Rosén M. \& Haglund B. (2005): From healthy survivors to sick survivors - implications for the twenty - first century. Scandinavian Journal of Public Health 33, 151 - 155.

[17] Rosenberg I.H. (2000) Nutrition and ageing. In Human Nutrition and Dietetics (J. Garrow, W. James \& A. Ralph, eds). Harcourt Publishers, London, pp.

[18] Roubenoff R. (2000): Sarcopenia and its implications for the elderly. European Journal of Clinical Nutrition 54, 40 - 47.

[19] Samson M.M., Meeuwsen I.B., Crowe A. \& Dessens J.A. (2000): Relationships between physical performance measures, age, height and body weight in healthy adults. Age and Ageing 29, 235 - 242.

[20] Sidenvall B., Lennernäs M. \& Ek A. - C. (2006): Elderly patients $\square$ meal patterns - a retrospective study. Journal of Human Nutrition and Dietetics 9, 263-272. Symreng T. (1982): Arm anthropometry in a large reference population and in surgical patients. Clinical Nutrition 1, 211-219.

[21] Soyombo, O. (1996) 'Writing a Research Report' in Ahonsi, B. \& Soyombo, O. (eds.) Readings in Social research Methods and Applications. Ibadan. Caltop Publications Linited.

[22] Soyombo, O. (2003) 'Doing Research in Social Research' in Olurode, L. \& Soyombo O. (eds.) Sociology for Beginners. Ikeja: John West Publications.

[23] Vandevijvere S., De Vriese S., Huybrechts I., Moreau M., Temme E., De Henauw S., De Backer G., Kornitzer M., Leveque A. \& Van Oyen H. (2008): The gap between food-based dietary guidelines and usual food consumption in Belgium, 2004. Public Health Nutrition 12, 423-431.

[24] Wikby K., Ek A.-C. \& Christensson L. (2006): Nutritional Status in Elderly People Admitted to Community Residential Homes: Comparison Between two Cohorts. The Journal of Nutrition, Health and aging 10, 232- 238 . 